\title{
Вмј Global Health Off the back burner: diverse and gender-inclusive decision-making for COVID-19 response and recovery
}

\author{
Sulzhan Bali (D) , ${ }^{1}$ Roopa Dhatt, ${ }^{1}$ Arush Lal, ${ }^{1}$ Amina Jama, ${ }^{2,3}$ Kim Van Daalen, ${ }^{4}$ \\ Devi Sridhar, ${ }^{5}$ Gender and COVID-19 Working Group
}

To cite: Bali S, Dhatt R, Lal A, et al. Off the back burner: diverse and genderinclusive decision-making for COVID-19 response and recovery. BMJ Global Health 2020;5:e002595. doi:10.1136/ bmjgh-2020-002595

Received 4 April 2020 Revised 13 April 2020 Accepted 13 April 2020

Check for updates

(c) Author(s) (or their employer(s)) 2020. Re-use permitted under CC BY. Published by BMJ.

${ }^{1}$ Women in Global Health, Washington, DC, USA

${ }^{2}$ Somali Institute for Development Research and Analysis (SIDRA), Nairobi, Kenya ${ }^{3}$ Women in Global Health, Mogadishu, Somalia ${ }^{4}$ Department of Public Health and Primary Care, University of Cambridge, Cambridge, UK ${ }^{5}$ Medical School, The University of Edinburgh, Edinburgh, UK

Correspondence to Professor Devi Sridhar; devi.sridhar@ed.ac.uk
Epidemics function as a gendered vulnerability, and yet gender remains an afterthought in health security and pandemic response, including to coronavirus disease 2019 (COVID-19). ${ }^{1}$ Emerging data indicate that COVID-19 mortality is greater among men, but past experiences suggest that the socioeconomic impact of epidemics tends to be far greater for women. As a result, it is essential to assess the intersectional and gendered vulnerabilities in health emergencies. In addition, given the gender-skewed landscape of power and decision-making in global health, it is also critical to outline women's leadership and role in such contexts.

Women are users of health services, and they are agents of change in health, making critical contributions as parents, front-line responders, health promoters, influencers, researchers, scientists and decision-makers. In China's COVID-19 response, female nurses and community health workers were the first line of defence against the outbreak. ${ }^{1}$ Despite their major role, an interplay of power and privilege often results in women-particularly women from minority ethnic groupsbeing under-represented in health and humanitarian leadership, even when women and such minorities are disproportionately affected. This is similarly the case for women from other under-represented groups such as indigenous people, in low and middle-income countries (LMIC) and sexual minorities or lesbian, gay, bisexual, transgender, queer and intersex (LGBTQI) individuals.

Regardless of constituting over $70 \%$ of the global health workforce, women hold only $25 \%$ of leadership roles in health. ${ }^{2}$ Further, women's scientific expertise is often excluded in the public realm even though they are more engaged in science outreach. ${ }^{3}$ The imbalance in diversity and equity, at the intersection of gender and LMIC representation,

\section{Summary box}

- Epidemics are a gendered vulnerability, with their socioeconomic impact disproportionately high among women, even when, as it seems the case with COVID-19, mortality is higher among men.

- However, women are not only a vulnerable population, they can serve as agents of change whose contributions can improve epidemic response and recovery.

- In COVID-19 response and recovery, existing lack of diversity and gender representation in decisionmaking means perspectives of some of the most vulnerable communities are left out.

- The evidence and lessons from peace, disaster and business sectors suggest that lack of diversity and failing to leverage women's expertise and talent in decision-making can limit an effective response.

- In addition to being ethical, diverse and gender inclusive decision-making will yield innovation and knowledge dividends, limit group-think and promote greater accountability for an adaptive response and resilient recovery to COVID-19.

is also mirrored in publications and editorial boards of major global health journals. ${ }^{45} \mathrm{~A}$ recent breakdown of WHO Expert Advisory Panels shows that only $34 \%$ of members were women and only $11 \%$ of members were from the African region, compared with $29 \%$ of members from the European region. ${ }^{6}$ These patterns of inequality in decision-making are then reflected in who sets the research priorities that inform policy, and who makes the policy decisions in COVID-19 response and recovery.

The lack of representation in agenda setting and decision-making matters because women face a triple burden in pandemics-high risk of exposure to nosocomial infections in their role as healthcare workers; lost opportunities due to school closures and increased unpaid family care; and heightened risk of ill health due to diverted resources and the cascading 


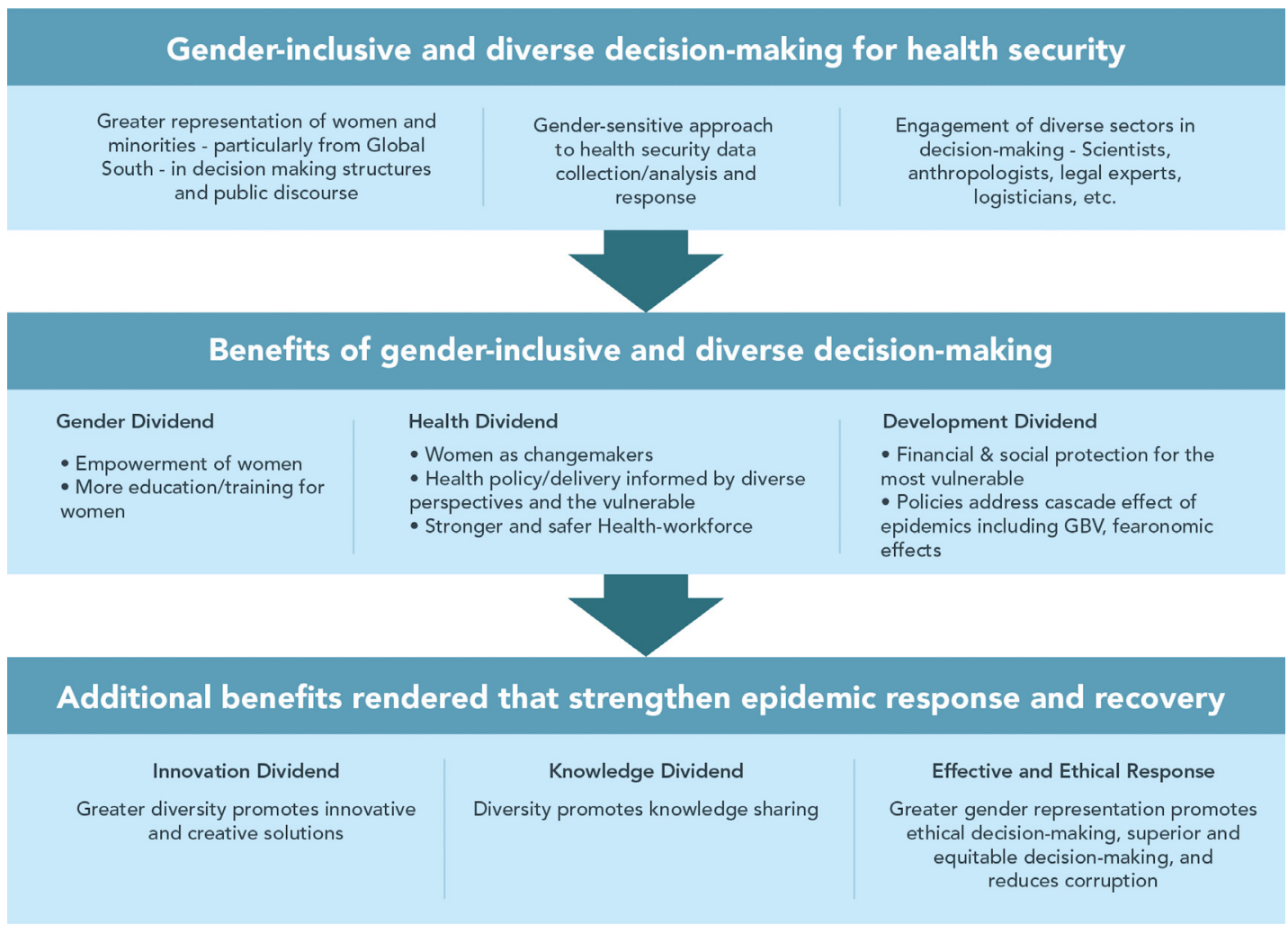

Figure 1 How greater gender representation and diversity in decision-making strengthens COVID-19 and other epidemic responses. GBV, Gender-Based Violence.

effects of pandemics. ${ }^{1}$ In the context of COVID-19, women and sexual minorities can also face a higher risk of Gender-Based Violence (GBV). Additionally, women constitute a majority of workers in the non-agricultural informal sector ${ }^{7}$-leaving them vulnerable to loss of livelihood and economic insecurity due to the disruptive 'fearonomic effects' of pandemics. ${ }^{8}$ The socioeconomic impact of disasters and crises is further exacerbated for women in minority and lower income groups. ${ }^{9}$ As mothers, women are more likely to be responsible for nearly 1.5 billion children who are out of school in times of widespread school disruptions-drastically impacting their ability to be financially independent. ${ }^{10}$

Epidemics further exacerbate other profound security, mental health and health risks in countries facing protracted conflicts with widespread gender inequality and general societal and economic disruption, due to weakened infrastructure and reduced access to health services. Lack of diversity and gender representation in decision-making at global, country and organisational levels means perspectives of some of the most vulnerable communities-including refugees and migrants, ethnic and sexual minorities-are often left out, limiting an effective response by failing to address the direct and indirect effects on women and girls and minorities, and failing to leverage their expertise and talent when it is needed most.

Gender-equal representation is more than just a moral imperative. When gender representation moves beyond pure symbolism, it leads to smarter, ethical and more effective decision-making-especially in crises. Evidence from peace and security studies shows that although peace processes led by women were $35 \%$ more likely to last, less than $13 \%$ of peace negotiators selected are women. ${ }^{11}$ Inclusion of women in decision-making advances stability and security, community trust and financial accountability, and focuses more on reducing inequities. Additionally, evidence from the business sector highlights the strong association of gender diversity with innovative and ethical decision-making, and with reduction in fraud and cognitive biases. ${ }^{12-15}$ Greater gender representation brings with it diverse perspectives and approaches to problem solving, resulting in faster and better quality decisions. $^{1617}$

For epidemic response to be effective and adaptive, perspectives of women, and LMICs and vulnerable communities are critical. Interventions that work in highincome countries may not work elsewhere. For example, border closures will have limited applicability in countries with porous borders, and top-down interventions may be less effective in countries where the community trust in governments is lower, particularly in areas where women have been mistreated by police and armed forces. Insights from the implementation of interventions in LMICs (for COVID-19 and previous disease outbreaks) and country-specific context that takes into perspectives of women, and vulnerable communities can greatly inform the COVID-19 response and recovery. A diverse decision-making body for health security and COVID-19 response, with expertise from LMICs, women, patient 
groups, indigenous people and the LGBTQI community, will limit group-think, boost problem solving, accountability and learning to unleash overlooked and innovative context-appropriate solutions to global challenges.

The same people who are engaged in response today will be the ones leading recovery and preparedness efforts tomorrow. Measures to promote gender equity, and representation in decision-making at all levels such as those proposed in the 'COVID 50/50 Five Asks for Gender-Responsive Health Security' will strengthen both global and local COVID-19 efforts and ensure greater engagement of those who are most affected in planning of response and recovery. ${ }^{18}$ In addition, mainstreaming gender in data collection and policy instruments such as the Joint External Evaluations and greater inclusion of women-particularly women from LMICs-in decisionmaking at the global level and in public discourse will ensure that we reap the innovation and knowledge dividends through smarter and creative decision-making for an effective COVID-19 response and a resilient postCOVID-19 future (see figure 1).

Twitter Sulzhan Bali @sulzhan

Acknowledgements The authors are grateful to Marie Prevot for her help with the graphic design and to Katie Gorham, Bonnie Jenkins, Laura Jung, Ann Keeling, Alexandra Phelan, Sarah Hillware and the Gender and COVID-19 Working Group for their initial thoughts and inputs.

Collaborators The Gender and COVID-19 Working Group is a network of interdisciplinary stakeholders interested in advancing research and practice related to COVID-19 coordinated by Clare Wenham (London School of Economics), Rosemary Morgan (John Hopkins University) and Julia Smith (Simon Fraser University). Other members include: Arne Ruckert (University of Ottawa), Sabra Klein (John Hopkins University), Madeline Johnson and Chris Berzins (Global Affairs Canada), Sulzhan Bali (Women in Global Health), Karen Grepin (University of Hong Kong), Susan Mackay (GAVI), Denise Nacif Pimenta (Oswaldo Cruz Foundation), Niyati Shah (USAID), Kelly Thompson (independent consultant), Sabine OerteltPrigione (Radboud University), Amber Peterman (University of North Carolina and UNICEF Innocenti), Ruth Kutalek (Medizinischen Universität Wien), Sophie Harman (QMUL), Ilana Lowy (French National Centre for Scientific Research), Nazeen Damji (UN Women), Ann Keeling (Women in Global Health), Kate Hawkins (Pamoja Communications), Myra Betron (Jhpiego), Susan Bell (Drexel University), Manasee Mishra (IIHMR University, India), Sean Hillier (York University), Evelyne Bischof (Shanghai University of Medicine and Health Sciences, Federico II University, Napoli, Italy, and Women's Brain Project). More members have joined since this piece was written.

Contributors SB and RD conceptualised the piece. AL, AJ, KVD, RD and DS provided critical inputs. SB, AL and KVD created the figure. SB wrote the first draft and consolidated inputs from coauthors.

Funding The authors have not declared a specific grant for this research from any funding agency in the public, commercial or not-for-profit sectors.
Disclaimer The views expressed in this article are those of the authors alone and do not represent the policies or views of the affiliated institutions.

Competing interests None declared.

Patient consent for publication Not required.

Provenance and peer review Not commissioned; externally peer reviewed.

Data availability statement Data are available upon request.

Open access This is an open access article distributed in accordance with the Creative Commons Attribution 4.0 Unported (CC BY 4.0) license, which permits others to copy, redistribute, remix, transform and build upon this work for any purpose, provided the original work is properly cited, a link to the licence is given, and indication of whether changes were made. See: https://creativecommons.org/ licenses/by/4.0/.

\section{ORCID iD}

Sulzhan Bali http://orcid.org/0000-0002-1146-9512

\section{REFERENCES}

1 Wenham C, Smith J, Morgan R, et al. COVID-19: the gendered impacts of the outbreak. Lancet 2020;395:846-8.

2 Boniol M, Mclsaac M, Xu L, et al. Gender equity in the health workforce: analysis of 104 countries. World Health Organization, 2019.

3 McCullagh EA, Nowak K, Pogoriler A, et al. Request a woman scientist: a database for diversifying the public face of science. PLOS Biol 2019;17:e3000212.

4 Nafade V, Sen P, Pai M. Global health journals need to address equity, diversity and inclusion. BMJ Glob Health 2019;4:e002018.

5 Bhaumik S, Jagnoor J. Diversity in the editorial boards of global health journals. BMJ Glob Health 2019;4:e001909.

6 WHO. Who expert Advisory panels and committees, 2018. Available: https://www.who.int/about/collaborations/expert_panels/en/

7 UN Women. Transforming economies, Realizing rights: progress of the world's women 2015-2016, 2015.

8 Bali S, Stewart KA, Pate MA. Long shadow of fear in an epidemic: fearonomic effects of Ebola on the private sector in Nigeria. BMJ Glob Health 2016;1:e000111.

9 Enarson E, Fothergill A, Peek L. Gender and disaster: foundations and new directions for research and practice. Springer: Handbook of disaster research, 2018: 205-23.

10 Valerie S. 1.5 billion children around globe affected by school closure. Washington Post, 2020.

11 O'Reilly M, AÓ S, Paffenholz T. Reimagining peacemaking: Women's roles in peace processes. New York: International Peace Institute, 2015: 31.

12 Cumming D, Leung TY, Rui O. Gender diversity and Securities fraud. Acad Manage J 2015;58:1572-93.

13 Cheng JY-J, Groysberg B. Gender diversity at the board level can mean innovation success. . MIT Sloan Management Review, 2020: 61. 1-8.

14 Phillips KW. How diversity makes us smarter. Sci Am 2014;311:43-7.

15 Rock D, Grant H. Why diverse teams are smarter. . Harvard Business Review, 2016: 4. 2-5.

16 Larson E. Hacking diversity with inclusive decision making, 2017.

17 Larkin MB. Board gender diversity, corporate reputation and market performance. Int J Bank Finance 2020;9:1-26.

18 Dhatt R. Opinion: global health security depends on women Devex, 2020. Available: https://www.devex.com/news/opinion-globalhealth-security-depends-on-women-96861 